\title{
Transferrin-binding ability of invasive and commensal isolates of Haemophilus spp.
}

\author{
K. R. HARDIE, R. A. ADAMS and K. J. TOWNER* \\ Department of Microbiology and PHLS Laboratory, University Hospital, Queen's Medical Centre, \\ Nottingham NG7 $2 \mathrm{UH}$
}

\begin{abstract}
Summary. Haemophilus influenzae type b expresses an inducible siderophore-independent iron-acquisition system that depends on a direct interaction between human transferrin and specific iron-regulated transferrin-binding outer-membrane proteins. To evaluate the importance of this iron-acquisition system amongst haemophili, 156 isolates of Haemophilus spp. (78 commensal isolates and 78 isolates from invasive infections) were examined for their ability to bind transferrin. Of the 78 invasive isolates, all of which were $H$. influenzae type b, $71(91 \%)$ were capable of binding transferrin, with $57(73 \%)$ binding transferrin constitutively (i.e., even when grown in an iron-sufficient medium). In contrast, only $11(14 \%)$ of the commensal isolates bound transferrin constitutively, with a further $16(21 \%)$ binding transferrin only after growth in an iron-deficient medium. Of the 27 commensal strains that were capable of binding transferrin, 12 were $H$. parainfluenzae biotype III, 14 were nontypable $H$. influenzae, and one was $H$. parahaemolyticus. None of the $H$. influenzae type b invasive or commensal isolates showed evidence of siderophore production, but $50(66 \%)$ of the remaining 76 commensal isolates appeared to produce an iron chelator. Thus, while not a universal characteristic, detectable transferrin-binding was associated strongly with $H$. influenzae type $\mathrm{b}$ isolates from invasive infections, and was also recognised for the first time in isolates of $H$. parainfluenzae and $H$. parahaemolyticus.
\end{abstract}

\section{Introduction}

Members of the genus Haemophilus are common commensals of the human upper respiratory tract, ${ }^{1}$ but they are also capable of causing a variety of infections in man, ranging from serious invasive disease to minor opportunist infections. Thus, while $H$. influenzae type $\mathrm{b}$ is the most important cause of meningitis, epiglottitis, pneumonia and otitis media in young children, ${ }^{2}$ other species such as $H$. parainfluenzae, $H$. parahaemolyticus, $H$. aphrophilus, $H$. paraphrophilus and $H$. segnis have been implicated, albeit infrequently, in a wide range of infections that includes pneumonia, septic arthritis, endocarditis, respiratory tract infection, bacteraemia and soft tissue infection. $^{3}$

To cause infection, an organism must first acquire sufficient essential nutrients to multiply in vivo. One such essential nutrient is iron, and the low concentration of free iron on the mucous membranes and in tissue fluids is one of the first lines of host defence against bacterial infection. ${ }^{4}$ Pathogenic bacteria have developed several mechanisms for circumventing this defence mechanism and acquiring the necessary iron

Received 28 Jan. 1993; accepted 12 Feb. 1993.

* Correspondence should be sent to Dr K. J. Towner. for growth from their host. The best studied of these mechanisms involves iron chelators, termed siderophores, that compete with the host iron-binding glycoproteins lactoferrin and transferrin for iron, and iron-repressible outer-membrane proteins that serve as receptors for iron-siderophore complexes. This type of high-affinity iron-transport system has been detected in a wide range of bacterial pathogens, ${ }^{5}$ including $H$. parainfluenzae and $H$. paraphrophilus. ${ }^{6}$ Other pathogens, notably Neisseria meningitidis and $H$. influenzae type $\mathrm{b}$, have been shown to express siderophore-independent iron-sequestering systems based on a direct interaction between host ironbinding glycoproteins, such as transferrin, and bacterial surface receptors (transferrin-binding proteins; TBPs). ${ }^{7-11}$

In laboratory-adapted isolates of $H$. influenzae type b, such as strain Eagan, ${ }^{12}$ expression of TBPs occurs only when iron is absent from the growth medium. ${ }^{11}$ In contrast, examination of a small number of fresh clinical isolates of $H$. influenzae type $\mathrm{b}$ from the blood and cerebrospinal fluid (CSF) of patients with meningitis has shown that TBPs are expressed constitutively, i.e., even in the presence of excess free iron. ${ }^{13}$ Therefore, it appears that the selective pressure of growth in the iron-restricted environment of blood or CSF may result in a regulatory switch leading to 
constitutive expression of the TBPs. The aim of the present study was to evaluate the overall importance of the TBP iron-acquisition system amongst haemophili by determining the transferrin-binding ability of human commensal and invasive isolates belonging to a range of different Haemophilus species and biotypes.

\section{Materials and methods}

\section{Bacteria}

Invasive clinical isolates of Haemophilus spp. were isolated on chocolate blood agar $^{14}$ in the routine diagnostic microbiology laboratory at University Hospital, Nottingham, from the blood cultures or CSF of patients suffering from meningitis (one strain/ patient). Commensal strains of Haemophilus spp. were

Table I. Biotyping scheme for isolates of $H$. influenzae and $H$. parainfluenzae

\begin{tabular}{|c|c|c|c|}
\hline \multirow{2}{*}{$\begin{array}{l}\text { Species and } \\
\text { biotype }\end{array}$} & \multicolumn{3}{|c|}{ Production of } \\
\hline & indole & urease & $\begin{array}{c}\text { ornithine } \\
\text { decarboxylase }\end{array}$ \\
\hline \multicolumn{4}{|c|}{$H$. influenzae $(\mathrm{X}+\mathrm{V}$-dependent $)$} \\
\hline I & + & + & + \\
\hline II & + & + & - \\
\hline III & - & + & - \\
\hline IV & - & + & + \\
\hline V & + & - & + \\
\hline VI & - & - & + \\
\hline VII & + & - & - \\
\hline VIII & - & - & - \\
\hline \multicolumn{4}{|c|}{ H. parainfluenzae (V-dependent only) } \\
\hline I & - & - & + \\
\hline II & - & + & + \\
\hline III & - & + & - \\
\hline IV & + & + & + \\
\hline V & - & - & - \\
\hline VI & + & - & + \\
\hline VII & + & + & - \\
\hline VIII & + & - & - \\
\hline
\end{tabular}

obtained from randomly selected routine throat swabs (one strain/patient) cultured initially on a selective medium comprising chocolate blood agar containing vancomycin $5 \mathrm{mg} / \mathrm{L}$. After overnight incubation at $37^{\circ} \mathrm{C}$ in $\mathrm{CO}_{2} 5 \%$ in air, putative colonies of Haemophilus spp. were subcultured to purity on chocolate blood agar. The laboratory-adapted strain of $H$. influenzae type b, strain Eagan, ${ }^{12}$ was kindly provided by Professor R. Moxon (Department of Paediatrics, John Radcliffe Hospital, Oxford). All haemophili were grown routinely on chocolate blood agar or in Brain Heart Infusion Broth (BHI; Oxoid CM225) supplemented with protoporphyrin IX (PPIX; Sigma) $0.5 \mathrm{mg} / \mathrm{L}$ and nicotinamide adenine dinucleotide (NAD; Sigma) $2 \mathrm{mg} / \mathrm{L}$ (sBHI). Strains of haemophili were stored at $-70^{\circ} \mathrm{C}$ in sBHI containing glycerol $10 \% \mathrm{v} / \mathrm{v}$.

\section{Identification of haemophili}

Initial species identification was based on the pattern of growth, after overnight incubation at $37^{\circ} \mathrm{C}$ in $\mathrm{CO}_{2}$ $5 \%$ in air, on Blood Agar Base No. 2 (Oxoid CM271) $4 \% \mathrm{w} / \mathrm{v}$ around disks containing $\mathrm{X}$-factor (haemin; Oxoid DD3), Y-factor (co-enzyme I; Oxoid DD4), or both (Oxoid DD5) ${ }^{15}$ combined with the results of biochemical tests performed in RapID NH System Panels for the identification of haemophili (Mercia Diagnostics, Guildford, Surrey). Subdivision into biotypes was based on tests for production of indole, urease and ornithine decarboxylase, ${ }^{1}$ but with the modified $H$. parainfluenzae groupings suggested by Taylor et $a .^{16}$ (table I). Isolates identified as $H$. influenzae were serotyped in a slide agglutination assay with capsular polyclonal and type b-specific antisera (Difco).

\section{Transferrin-binding assay}

This was based on the solid-phase dot enzyme assay

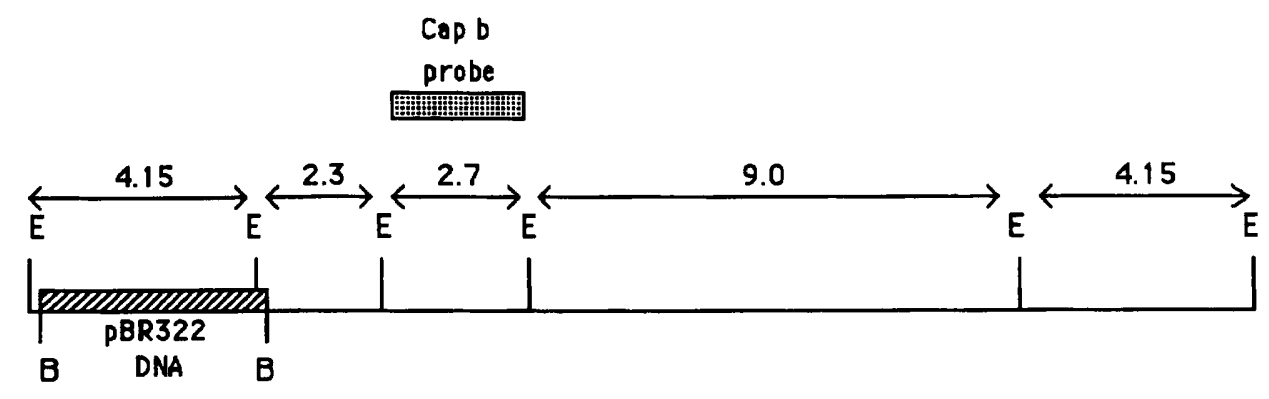


described by Morton and Williams. ${ }^{11}$ Strains of haemophili were first subcultured from chocolate-agar plates into sBHI containing $40 \mu \mathrm{M} \quad \mathrm{FeSO}_{4}$. After overnight growth at $37^{\circ} \mathrm{C}$ in this iron-enriched medium, $0 \cdot 1-\mathrm{ml}$ volumes were subcultured into: (i) $1 \mathrm{ml}$ of sBHI containing $40 \mu \mathrm{M} \mathrm{FeSO}$; and (ii) $1 \mathrm{ml}$ of sBHI containing $25 \mu \mathrm{M}$ ethylenediamine di- $o$ hydroxyphenylacetic acid (EDDA; Sigma) freed previously from contaminating iron as described by Rogers. ${ }^{17}$ After overnight incubation, the cells were harvested by centrifugation in microfuge tubes, resus-

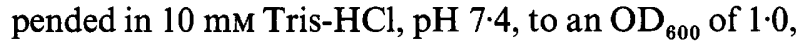
and 5- $\mu \mathrm{l}$ spots were applied to a nitrocellulose membrane $(0.45 \mu \mathrm{m}$ pore size; Sartorius, Epsom, Surrey). After drying at room temperature for $10 \mathrm{~min}$, the membrane was blocked for $1 \mathrm{~h}$ at room temperature with skimmed milk powder $1 \% \mathrm{w} / \mathrm{v}$ in TBS buffer (150 mM NaCl, $10 \mathrm{~mm}$ Tris, $\mathrm{pH} 7 \cdot 4$ ), washed twice for $2 \mathrm{~min}$ each in $100 \mathrm{ml}$ of TBS, and then incubated at room temperature for $2 \mathrm{~h}$ with a human transferrinhorseradish peroxidase conjugate (Stratech Scientific, Luton, Bedfordshire) at a final concentration of $100 \mathrm{ng} / \mathrm{ml}$ in TBS. After four washes (each for $2 \mathrm{~min}$ ) in $100 \mathrm{ml}$ of TBS, the membrane was developed with a solution consisting of $90 \mathrm{ml}$ of Tris- $\mathrm{HCl}, \mathrm{pH} \mathrm{7.4,10 \textrm {ml }}$ of methanol containing $0.1 \mathrm{~g}$ of 4-chloro-1-naphthol (Sigma), and $100 \mu \mathrm{l}$ of $\mathrm{H}_{2} \mathrm{O}_{2}$. Transferrin-binding was indicated by the development of a blue dot at the site of application of the cells, and was recorded as either "constitutive" (binding after growth in the presence or absence of EDDA), "inducible" (binding only after growth in the presence of EDDA), or "no binding".

\section{DNA hybridisation test for type $b$ capsular genes}

Preparation of Cap b DNA probe. Plasmid pUO38 (kindly provided by Dr J. S. Kroll, Department of Paediatrics, John Radcliffe Hospital, Oxford) consists of the vector plasmid pBR322 into which has been cloned a BamHI fragment of $c .18 \mathrm{~kb}$ containing part of the Cap b region of $H$. influenzae strain Eagan. ${ }^{18}$ Fig. 1 shows a partial restriction map of pUO38. Digestion with $E c o$ RI yields four visible bands after agarose gel electrophoresis: (i) $9.0 \mathrm{~kb}$; (ii) two comigrating fragments, one of which is mostly pBR322 vector DNA, of c. $4 \cdot 15 \mathrm{~kb}$; (iii) $2 \cdot 7 \mathrm{~kb}$; and (iv) $2 \cdot 3 \mathrm{~kb}$. Of these, the $2 \cdot 7-\mathrm{kb}$ fragment has been shown to form a specific probe for serotype $b$ strains.$^{18}$ This fragment was prepared, purified, and labelled with biotin-14dATP (Gibco BRL) as described previously. ${ }^{19}$

Hybridisation experiments. Total cellular DNA was isolated from strains of haemophili by the method of Moxon et al. $;^{20}$ each microfuge tube preparation of DNA was dissolved finally in $100 \mu \mathrm{l}$ of TE buffer (10 mM Tris, $1 \mathrm{~mm}$ EDTA, pH 8.0). DNA was then applied (5- $\mu$ l spots) to a nitrocellulose membrane, airdried, and baked at $80^{\circ} \mathrm{C}$ for $2 \mathrm{~h}$ to bind the DNA to the membrane. Before hybridisation, membranes were re-hydrated and treated with proteinase K (Sigma) as described by Carter et al. ${ }^{19}$ Pre-hybridisation and hybridisation with the labelled probe was also as described previously. ${ }^{19}$ Detection of a positive hybridisation result was by means of a BlueGENE Kit (Gibco BRL) with the conditions and protocols recommended by the manufacturer.

\section{Ability of transferrin to restore growth in iron- restricted liquid media}

This was based on the method described by Holland et al. ${ }^{21}$ with the additional step that the internal iron pools of the haemophili tested were first depleted by overnight growth at $37^{\circ} \mathrm{C}$ in sBHI containing $25 \mu \mathrm{M}$ EDDA. These "iron-stressed" cultures were then used to inoculate $250-\mathrm{ml}$ flasks containing: (i) $25 \mathrm{ml}$ of sBHI plus $40 \mu \mathrm{M} \mathrm{FeSO}_{4}$; (ii) $25 \mathrm{ml}$ of BHI plus $100 \mu \mathrm{M}$ EDDA (iron-restricted conditions); and (iii) $25 \mathrm{ml}$ of sBHI plus $100 \mu \mathrm{M}$ EDDA plus $90 \%$ iron-saturated human transferrin (Sigma) at $200 \mu \mathrm{g} / \mathrm{ml}$. The flasks were incubated at $37^{\circ} \mathrm{C}$ on an orbital shaker at $220 \mathrm{rpm}$. Growth was monitored at $\mathrm{OD}_{600}$.

\section{Rapid test for siderophore production}

This was adapted for haemophili from the method described by Schwyn and Neilands. ${ }^{22}$ Siderophore assay agar for haemophili was prepared as follows: for each $100 \mathrm{ml}$ of agar, $12.1 \mathrm{~g}$ of Chrome Azurol S Dye (Mordant blue 29; Sigma) was added to $5 \mathrm{ml}$ of $\mathrm{H}_{2} \mathrm{O}$, followed by the addition of $1 \mathrm{ml}$ of an iron solution $\left(1 \mathrm{mM} \mathrm{FeCl}{ }_{3}, 10 \mathrm{mM} \mathrm{HCl}\right)$. This solution was then added to $14.58 \mathrm{mg}$ of cetrimide (mixed alkyl trimethylammonium bromide; Sigma) dissolved in $4 \mathrm{ml}$ of $\mathrm{H}_{2} \mathrm{O}$. The resulting blue solution was autoclaved. Concomitantly, a solution containing $3.3 \mathrm{~g}$ of dehydrated BHI, $1.5 \mathrm{~g}$ of Bacto Agar (Difco), 3.034 $\mathrm{g}$ of PIPES (Sigma), $1.2 \mathrm{ml}$ of $\mathrm{NaOH} 50 \% \mathrm{w} / \mathrm{v}$, and $0.1 \mathrm{ml}$ of $\mathrm{L}-\alpha-$ phosphatidyl-choline (Sigma) $10 \% \mathrm{w} / \mathrm{v}$ in $88 \mathrm{ml}$ of $\mathrm{H}_{2} \mathrm{O}$ was also autoclaved. The two solutions were cooled to $50^{\circ} \mathrm{C}$, mixed to produce a green agar solution, and then supplemented with PPIX and NAD, as described earlier, immediately before pouring agar plates. Once the agar had set, it was inoculated with 5$\mu l$ spots of cultures grown overnight at $37^{\circ} \mathrm{C}$ in sBHI containing $25 \mu \mathrm{M}$ EDDA. Incubation was at $37^{\circ} \mathrm{C}$ for up to $48 \mathrm{~h}$. The presence of a yellow zone around an inoculum spot indicated the production of a high affinity iron chelator, i.e., a siderophore.

\section{Results}

\section{Identification and transferrin-binding ability of haemophili}

All of 78 invasive isolates were identified as $H$. influenzae type b. A corresponding total of 78 commensal isolates was obtained after screening cultures 
Table II. Transferrin-binding ability of invasive and commensal isolates of Haemophilus spp.

\begin{tabular}{|c|c|c|c|c|}
\hline \multirow{2}{*}{ Species } & \multirow{2}{*}{$\begin{array}{c}\text { Total } \\
\text { number } \\
\text { of strains }\end{array}$} & \multicolumn{3}{|c|}{$\begin{array}{l}\text { Number of strains with } \\
\text { transferrin-binding ability }\end{array}$} \\
\hline & & Constitl & aduc & $o$ binding \\
\hline \multicolumn{5}{|l|}{ Invasive isolates $(78)$} \\
\hline \multicolumn{4}{|l|}{ H. influenzae type b } & 7 \\
\hline \multicolumn{5}{|c|}{ Commensal isolates $(78)$} \\
\hline Biotype I & 2 & 0 & 0 & 2 \\
\hline \multicolumn{5}{|c|}{ H. influenzae non-typable } \\
\hline Biotype I & 21 & 1 & 6 & 14 \\
\hline Biotype II & 4 & 1 & 1 & 2 \\
\hline Biotype III & 5 & 0 & 3 & 2 \\
\hline Biotype IV & 1 & 0 & 1 & 0 \\
\hline Biotype V & 1 & 0 & 1 & 0 \\
\hline Biotype VI & 1 & 0 & 0 & 1 \\
\hline Biotype VII & 1 & 0 & 0 & 1 \\
\hline \multicolumn{5}{|l|}{ H. parainfluenzae } \\
\hline Biotype I & 3 & 0 & 0 & 3 \\
\hline Biotype II & 5 & 0 & 0 & 5 \\
\hline Biotype III & 28 & 8 & 4 & 16 \\
\hline H. segnis & 5 & 0 & 0 & 5 \\
\hline H. parahaemolyticus & 1 & 1 & 0 & 0 \\
\hline
\end{tabular}

from 410 routine throat swabs. Of these commensal isolates, two were $H$. influenzae type b, 34 were nontypable $H$. influenzae, 36 were $H$. parainfluenzae, five were $H$. segnis, and one was $H$. parahaemolyticus. Subdivision of these strains into biotypes is shown in table II.

Fig. 2 shows an example of the solid-phase dot enzyme assay to illustrate the distinction between "constitutive", "inducible" and "no binding" of transferrin. Of the 78 invasive isolates, $71(91 \%)$ were capable of binding transferrin, with $57(73 \%)$ binding transferrin constitutively, i.e., even when grown in an iron-sufficient medium (table II). Seven invasive isolates of $H$. influenzae type $\mathrm{b}$ were identified that, in repeated experiments, did not appear to bind transferrin when grown in either the presence or absence of iron. Of the 78 commensal isolates, $11(14 \%)$ strains bound transferrin constitutively. These comprised two non-typable $H$. influenzae isolates belonging to biotype I, eight $H$. parainfluenzae isolates belonging to biotype III, and one isolate of $H$. parahaemolyticus. A further $16(21 \%)$ strains were capable of binding transferrin after growth in an iron-deficient medium. These comprised 12 non-typable $H$. influenzae isolates belonging to five different biotypes, and four $H$. parainfluenzae isolates belonging to biotype III. Two commensal isolates of $H$. influenzae type $\mathrm{b}$ failed to bind transferrin in either the presence or absence of iron (table II).

\section{Analysis of isolates by DNA hybridisation with a type- $b$ capsular probe}

Direct binding of transferrin by human-associated haemophili other than $H$. influenzae type b has not been reported previously. Hybridisation with the DNA probe derived from pUO38 allows the identification of non-capsulate $\left(b^{-}\right)$progeny of type $b$ strains. ${ }^{23}$ All 98 strains that were capable of binding transferrin, plus the nine strains identified as $H$.

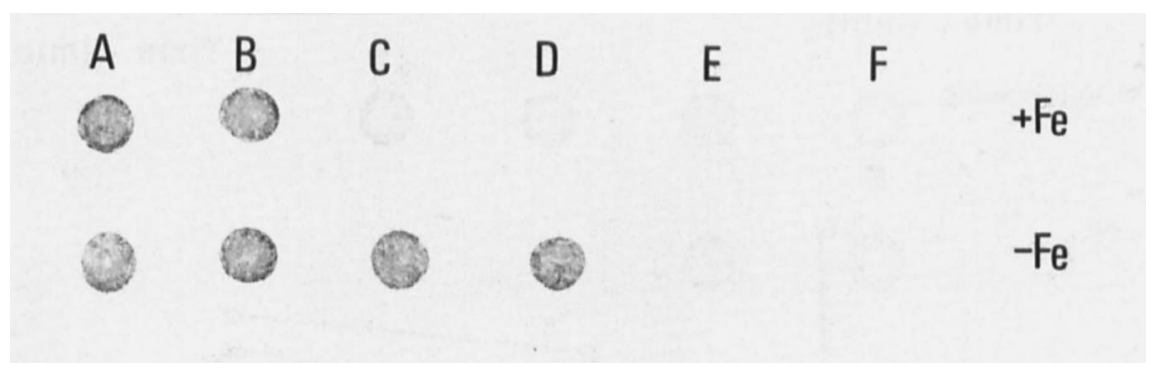

Fig. 2. Example of the solid-phase dot enzyme assay illustrating the distinction between "constitutive" (strains A and B), "inducible" (strains $\mathrm{C}$ and D) and "no binding" (strains E and F) of transferrin. Cultures were grown in the presence ( $+\mathrm{Fe})$ or absence $(-\mathrm{Fe})$ of iron as described in Materials and methods.

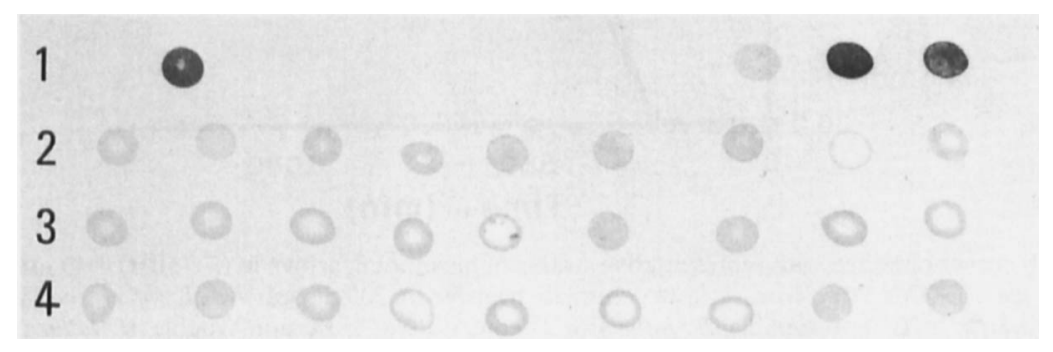

Fig. 3. Example of results obtained in dot-blot hybridisation experiments with the probe specific for Cap b. The blot shown contains total genomic DNA from 31 isolates, including the 27 "transferrin-binding" strains which were not $H$. influenzae type b (lines $2-4$ ). The top line of four isolates comprises (left to right): H. influenzae type b strain Eagan; $E$. coli $\mathrm{K} 12$ negative control; two invasive isolates of $H$. influenzae type b from CSF. 

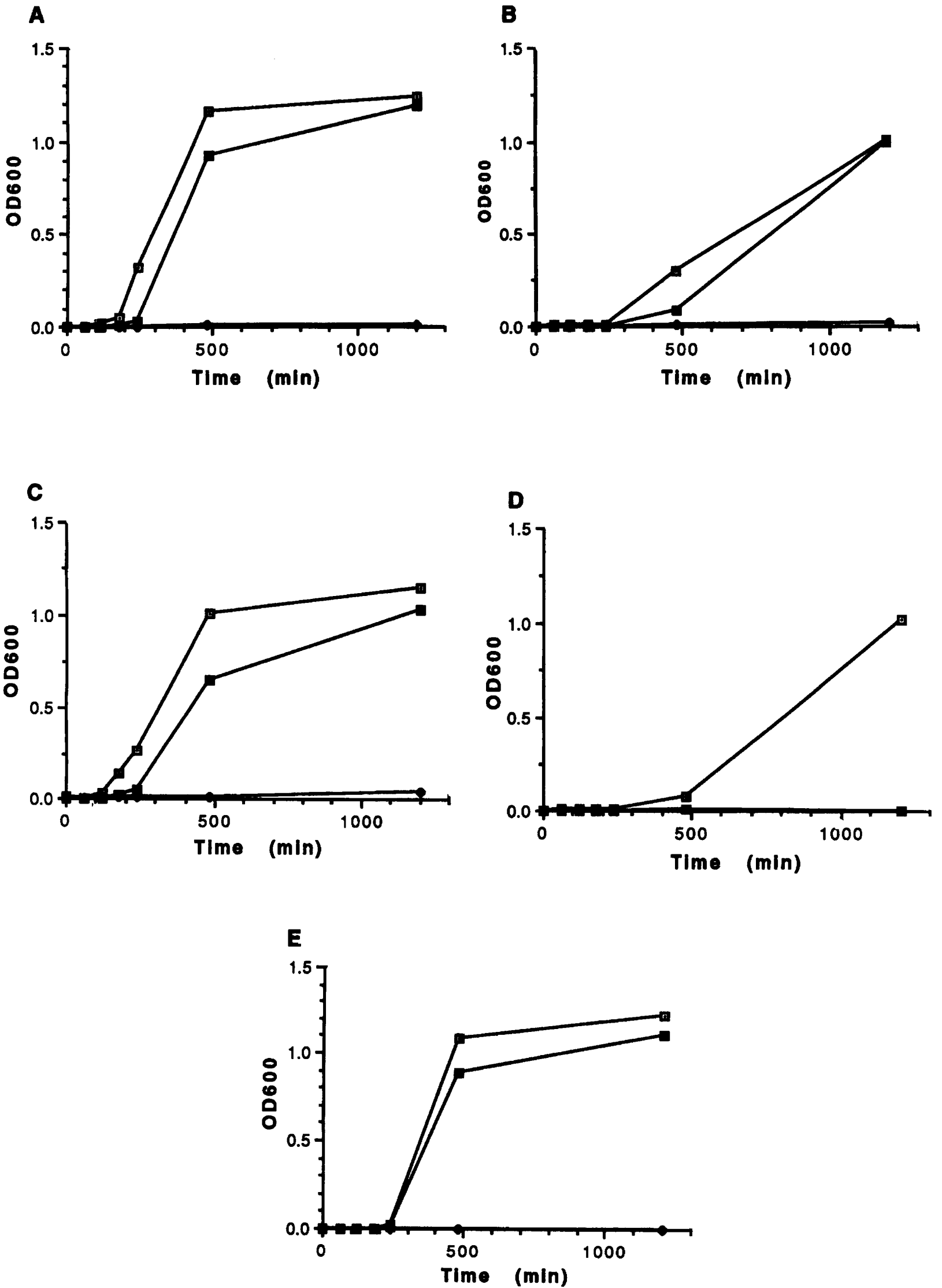

Fig. 4. Examples of growth curves obtained with representative strains of haemophili grown in () $\mathrm{sBHI}+40 \mu \mathrm{M} \mathrm{FeSO} \mathrm{O}_{4} ;(\mathrm{O}) \mathrm{sBHI}+100 \mu \mathrm{M}$ EDDA; ( $)$ sBHI $+100 \mu \mathrm{M}$ EDDA $+90 \%$ iron-saturated human transferrin $200 \mu \mathrm{g} / \mathrm{ml}$. A, H. influenzae type b ("inducible"); B, $H$. influenzae type b ("no binding"); C, non-typable $H$. influenzae ("constitutive"); D, non-typable $H$. influenzae ("no binding"); $\mathbf{E}, H$. parainfluenzae ("constitutive"). 
influenzae type $b$ that did not bind transferrin, were tested in dot-blot hybridisation experiments with the probe derived from pUO38 that was specific for Cap $b$. All 80 strains identified as $H$. influenzae type b, including the nine strains that failed to bind transferrin, generated a positive hybridisation signal with the probe. The remaining 27 "transferrin-binding" strains failed to hybridise with the probe (fig. 3).

\section{Restoration of growth by transferrin in iron-restricted broth cultures}

Representative strains from each group of isolates were tested for their ability to obtain iron from transferrin when grown in iron-restricted broth cultures. Examples of the results obtained are shown in fig. 4. All of the tested strains that were capable of binding transferrin were also capable of obtaining the necessary iron from transferrin for growth in broth cultures (e.g. fig. 4A,C,E). Unexpectedly, all nine of the $H$. influenzae type b strains that did not appear to bind transferrin were still capable of obtaining iron from transferrin (e.g., fig. 4B), but the non-typable $H$. influenzae strains that did not bind transferrin were unable to obtain iron from transferrin in liquid medium (e.g., fig. 4D).

\section{Siderophore production}

Apart from a direct binding mechanism, an alternative method of obtaining iron from transferrin might involve the production of diffusible siderophores. Using the rapid agar test for siderophore production, none of the $H$. influenzae type $b$ isolates was identified as a producer of siderophores, but $18(53 \%)$ of the non-typable $H$. influenzae isolates generated yellow zones around the inoculum spot, indicating the presence of a diffusible iron chelator. Similarly, amongst the $36 \mathrm{H}$. parainfluenzae isolates, $27(75 \%)$ gave positive results, as did all five of the $H$. segnis isolates. With the exception of the nine $H$. influenzae type $\mathrm{b}$ isolates referred to above, strains that were nontransferrin-binding and that did not appear to produce siderophores were unable to obtain iron from transferrin in iron-restricted broth cultures.

\section{Discussion}

Haemophili are known to express various ironuptake mechanisms, including the siderophoredependent iron-sequestering systems possessed by $H$. parainfluenzae and $H$. paraphrophilus, ${ }^{6}$ and the direct transferrin receptor-mediated iron acquisition system possessed by $H$. influenzae. ${ }^{11,24}$ In the present study it was confirmed that the majority of $H$. influenzae type $b$ isolates from invasive infections, as well as a smaller proportion of non-typable commensal isolates, were capable of binding human transferrin and using it as a source of iron. Furthermore, transferrin-binding ability was also identified, for the first time, in isolates of $H$. parainfluenzae and $H$. parahaemolyticus. Although previous studies with a limited number of isolates have failed to identify this property in $H$. parainfluenzae, ${ }^{6,25}$ it is worth noting that transferrinbinding ability in $H$. parainfluenzae was confined in the present study to isolates belonging to biotype III. This biotype occurs relatively infrequently in the oropharyngeal flora ( $16 \%$ of $H$. parainfluenzae isolates from healthy controls in a recent study ${ }^{16}$ ), and, therefore, may not have been included in the previous surveys. However, the occurrence of transferrinbinding ability in human-associated members of the genus other than $H$. influenzae is not surprising since haemophili of animal origin also have been reported to bind transferrins derived from their respective hosts. ${ }^{26-29}$ Therefore, transferrin-binding ability may be a common property of species belonging to this genus, but one which is not necessarily shared by all individual isolates.

A previous study ${ }^{13}$ of fresh clinical isolates from the blood or CSF of 14 patients with meningitis found that transferrin binding was constitutive rather than ironregulated. It has been suggested that the selective pressure of growth in the iron-restricted environment of blood or CSF might lead to a regulatory switch that results in constitutive expression of the transferrin receptor. In the present study, $91 \%$ of the invasive $H$. influenzae type b isolates from 78 patients were capable of binding transferrin, with $73 \%$ binding transferrin constitutively. Only two commensal strains of $H$. influenzae type $\mathrm{b}$ were isolated (both of which failed to bind transferrin), but constitutive transferrin-binding ability was also identified in two non-typable isolates of $H$. influenzae, eight $H$. parainfluenzae isolates, and one $H$. parahaemolyticus isolate. Therefore, constitutive transferrin-binding ability is associated strongly with, but is not confined solely to, haemophili isolated from invasive disease.

Of particular interest were the seven invasive and two commensal isolates of $H$. influenzae type b that did not appear to bind transferrin after growth in either iron-sufficient or iron-deficient conditions. These strains were confirmed as type $b$ strains by hybridisation with the Cap b-specific DNA probe. There was no evidence that any of these strains produced siderophores, yet they were still able to multiply at normal rates when grown with transferrin in iron-restricted liquid medium. In this context, it is worth noting that six "non-binding" mutant derivatives, constructed in a separate study by an insertional mutagenesis procedure from a "constitutive" strain, were still able to obtain iron from transferrin when grown in ironrestricted liquid medium (K. J. Towner, unpublished results). Further studies are required to determine whether these "non-binding" strains remain capable of binding transferrin at low, undetectable levels, 
or whether some haemophili have the capacity to obtain iron from transferrin by an as yet undescribed mechanism.

The present study was concerned solely with analysing transferrin-binding ability rather than studying the nature of the transferrin receptor(s) in the different strains. The transferrin receptor in $H$. influenzae is thought to consist of at least two proteins - $a$ high $\mathrm{M}_{\mathrm{r}}$ protein of $c .100 \mathrm{kDa}$ (TBP1), and a lower $\mathrm{M}_{\mathrm{r}}$ protein (TBP2) that varies from $c .70$ to $90 \mathrm{kDa}$ depending on the strain examined..$^{8,11,24}$ Similar results have been reported for $N$. meningitidis, ${ }^{9,10,30}$ and the existence of shared antigenic domains in the TBPs of $H$. influenzae and $N$. meningitidi ${ }^{31}$ has raised the possibility that a single vaccine could confer protection against the two

\section{References}

1. Hoiseth SK. The genus Haemophilus. In: Balows A, Trüper HG, Dworkin M, Harder W, Schleifer K-H (eds) The prokaryotes. New York, Springer-Verlag. 1992: 3304-3330.

2. Turk DC. The pathogenicity of Haemophilus influenzae. J Med Microbiol 1984; 18: 1-16.

3. Albritton WL. Infections due to Haemophilus species other than H. influenzae. Annu Rev Microbiol 1982; 36: 199-216.

4. Otto BR, Verweij-van Vught AMJJ, MacLaren DM. Transferrins and heme-compounds as iron sources for pathogenic bacteria. Crit Rev Microbiol 1992; 18: 217-233.

5. Griffiths $E$. The iron-uptake systems of pathogenic bacteria. In: Bullen JJ, Griffiths E (eds) Iron and infection: molecular, physiological and clinical aspects. Chichester, Wiley. 1987: 69-137.

6. Williams P, Morton DJ, Towner KJ, Stevenson P, Griffiths E. Utilization of enterobactin and other exogenous iron sources by Haemophilus influenzae, $H$. parainfluenzae and H. paraphrophilus. J Gen Microbiol 1990; 136: 2343-2350.

7. Tsai J, Dyer DW, Sparling PF. Loss of transferrin receptor activity in Neisseria meningitidis correlates with inability to use transferrin as an iron source. Infect Immun 1988; 56: 3132-3138.

8. Schryvers AB. Identification of the transferrin- and lactoferrinbinding proteins in Haemophilus influenzae. J Med Microbiol 1989; 29: 121-130.

9. Ala'Aldeen DA, Davies HA, Wall RA, Borriello SP. The 70 kilodalton iron-regulated protein of Neisseria meningitidis is not the human transferrin receptor: FEMS Microbiol Lett 1990; 69: 37-42.

10. Griffiths E, Stevenson P, Ray A. Antigenic and molecular heterogeneity of the transferrin-binding protein of Neisseria meningitidis. FEMS Microbiol Lett 1990; 69: 31-36.

11. Morton DJ, Williams P. Siderophore-independent acquisition of transferrin-bound iron by Haemophilus influenzae type b. J Gen Microbiol 1990; 136: 927-933.

12. Anderson P, Johnson RB, Smith DH. Human serum activities against Haemophilus influenzae type b. J Clin Invest 1972; 51: $31-38$.

13. Holland J, Langford PR, Towner KJ, Williams P. Evidence for in vivo expression of transferrin-binding proteins in Haemophilus influenzae type b. Infect Immun 1992; 60: 2986-2991.

14. Cruickshank R (ed). Medical microbiology, 11th edn. Edinburgh, Churchill Livingstone. 1965: 748

15. Kilian M. Haemophilus. In: Lennette EH, Balows A, Hausler WJ, Truant JP (ed) Manual of clinical microbiology, 3rd edn. Washington, D.C., American Society for Microbiology. 1980: 330-336. major causes of bacterial meningitis. Such studies of antigenic relationships amongst TBPs have so far been performed with only a very limited number of strains. Preliminary results with the strains described in the present paper suggest that the TBPs from $H$. influenzae isolates in the Nottingham area are relatively conserved (K. R. Hardie, unpublished results), but further progress in this field will depend on detailed analysis of TBPs from isolates from a wide range of geographical locations.

This work was supported by a research grant to $K$. J. T. from the Trent Regional Health Authority. We are indebted to Dr J. S. Kroll for the gift of pUO38. We thank Drs J. Holland and P. Williams for their helpful advice on performing the transferrin-binding assays and tests for siderophore production.

16. Taylor DC, Cripps AW, Clancy RL et al. Biotypes of Haemophilus parainfluenzae from the respiratory secretions in chronic bronchitis. J Med Microbiol 1992; 36: 279-282.

17. Rogers HJ. Iron-binding catechols and virulence in Escherichia coli. Infect Immun 1973; 7: 445-456.

18. Ely S, Tippett J, Moxon ER. Identification and characterization of a serotype b-specific segment of the Haemophilus influenzae genome. Infect Immun 1989; 57: 2926-2928.

19. Carter GI, Towner KJ, Slack RCB. Detection of TEM betalactamase genes by non-isotopic spot hybridization. Eur $J$ Clin Microbiol 1987; 6: 406-409.

20. Moxon ER, Deich RA, Connelly C. Cloning of chromosomal DNA from Haemophilus influenzae. Its use for studying the expression of type b capsule and virulence. $J$ Clin Invest 1984; 73: 298-306.

21. Holland $\mathbf{J}$, Towner $\mathrm{KJ}$, Williams $\mathbf{P}$. Isolation and characterisation of Haemophilus influenzae type $\mathrm{b}$ mutants defective in transferrin-binding and iron assimilation. FEMS Microbiol Lett 1991; 77: 283-287.

22. Schwyn B, Neilands JB. Universal chemical assay for the detection and determination of siderophores. Anal Biochem 1987; 160: 47-56.

23. Kroll JS, Ely S, Moxon ER. Capsular typing of Haemophilus influenzae with a DNA probe. $\mathrm{Mol}$ Cell Probes 1991; 5: 375-379.

24. Schryvers AB. Characterization of the human transferrin and lactoferrin receptors in Haemophilus influenzae. Mol Microbiol 1988; 2: 467-472.

25. Herrington DA, Sparling PF. Haemophilus influenzae can use human transferrin as a sole source for required iron. Infect Immun 1985; 48: 248-251.

26. Morton DJ, Williams P. Utilization of transferrin-bound iron by Haemophilus species of human and porcine origins. FEMS Microbiol Lett 1989; 65: 123-128.

27. Gonzalez GC, Caamano DL, Schryvers AB. Identification and characterization of a porcine-specific transferrin receptor in Actinobacillus pleuropneumoniae. Mol Microbiol 1990; 4: 1173-1179.

28. Ogunnariwo JA, Cheng C, Ford J, Schryvers AB. Response of Haemophilus somnus to iron limitation: expression and identification of a bovine-specific transferrin receptor. Microb Pathog 1990; 9: 397-406.

29. Ogunnariwo JA, Schryvers AB. Correlation between the ability of Haemophilus paragallinarum to acquire ovotransferrinbound iron and the expression of ovotransferrin-specific receptors. Avian Dis 1992; 36: 655-663.

30. Schryvers AB, Morris LJ. Identification and characterization of the transferrin receptor from Neisseria meningitidis. $\mathrm{Mol}$ Microbiol 1988; 2: 281-288.

31. Stevenson $\mathbf{P}$, Williams $\mathbf{P}$, Griffiths E. Common antigenic domains in transferrin-binding protein 2 of Neisseria meningitidis, Neisseria gonorrhoeae, and Haemophilus influenzae type b. Infect Immun 1992; 60: 2391-2396. 